\title{
CCOP at 50: Half a Century of Regional Geoscience Cooperation
}

\author{
Nguyen Thi Minh $\operatorname{Ngoc}^{1}$, Simplicio Caluyong ${ }^{1}$, Marivic Pulvera Uzarraga ${ }^{1}$, Adichat Surinkum ${ }^{1}$, \\ Anthony Reedman ${ }^{2}$, Yongje Kim ${ }^{3}$ \\ ${ }^{1}$ CCOP Technical Secretariat, CCOP Building, 75/10 Rama VI Road Phayathai, Ratchathewi, Bangkok 10400, Thailand. E-mail: \\ ccopts@ccop.or.th \\ ${ }^{2}$ Honorary Adviser to CCOP, 15 Malvern Road, Mapperley, Nottingham NG3 5GZ United Kingdom; E-mail: antony@areedman.wanadoo.co.uk \\ ${ }^{3}$ Korea Institute of Geoscience and Mineral Resources (KIGAM); E-mail: yjkim@kigam.re.kr
}

\begin{abstract}
The Coordinating Committee for Geoscience Programmes in East and Southeast Asia (CCOP) celebrates its 'Golden Jubilee' this year. This article traces the growth of CCOP since its foundation in May 1966, highlighting the development of the CCOP Network, turning talk into action through CCOP Projects and pointing the way forward for geoscience in the service of society. International cooperation established through CCOP during many years has been the foundation many for many coordinated activities in geoscience to be implemented in the countries of southeast and east Asia.
\end{abstract}

\section{Beginning and growth of the organization in Asia}

Geoscience is inherently international in nature and geological formations do not recognize national boundaries. Though there had been many cases of international cooperation in geoscientific research in Asia since the late $19^{\text {th }}$ Century, these were mostly between individuals, at best sporadic and not very systematic.

The UN Economic Commission for Asia and the Far East (ECAFE) was established under the umbrella of the United Nations in thelate1940s, aiming to assist member countries in Asia to revive their economies after the devastation of World War II. The Mineral Resources Section of the Industry and Natural Resources Division of ECAFE was one of the organizations most active units in its early days. Their activities were implemented through two conference units serviced by the Mineral Resources Section and known respectively as the Subcommittee for Mineral Resources Development and the Working Party for Senior Geologists. The latter consisted mostly of representatives of the national geological surveys of the ECAFE region. The Working Party met every two to three years and was the only international forum in the region for the senior geological survey personnel. It could be said that it was from these meetings and some associated activities that the seeds were first sown that would, in time, lead to the formation of CCOP.

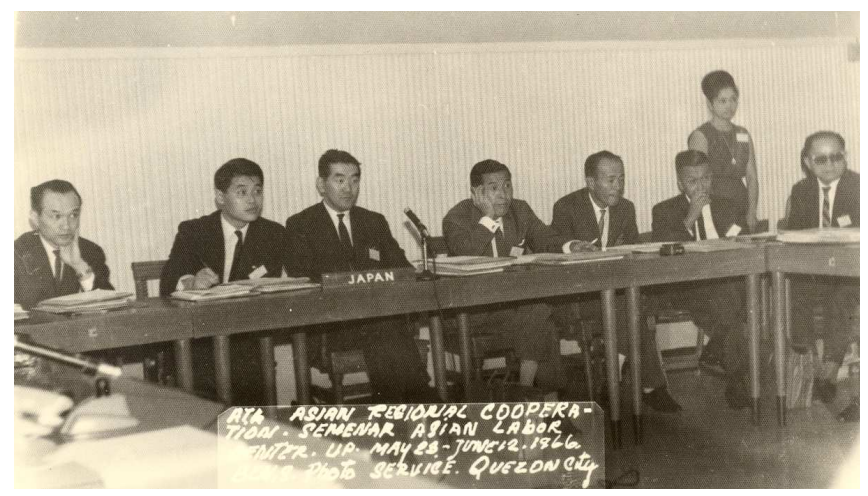

Figure 1. First CCOP session from 27 May to 2 June, 1966 in Quezon City, the Philippines
It was in the early 1960swhen a series of remarkable discoveries in marine geology became evident to the world's geoscientific community that a proposal regarding the possibilities for conducting joint offshore geophysical surveys of the continental shelf areas of the ECAFE region was first submitted by the ECAFE Secretariat to the $17^{\text {th }}$ session of its Committee on Industry and Natural Resources in February 1965. After some discussion it was agreed to set up an ad hoc Working Group of Experts to work out ways and means of facilitating exploration for oil, gas and other types of mineral deposits in the shallow marine shelf areas of the ECAFE region.

In July 1965, following a detailed review of the situation, the Working Group recommended that a 'coordinating committee' consisting of representatives of interested countries should be established and in November 1965, at a meeting in Tokyo convened in conjunction with the 'Third ECAFE Symposium on Development of Petroleum Resources', the Executive Secretary of ECAFE invited representatives of governments of all interested countries in Asia to consider what action might be taken in connection with the recommended establishment of a 'Committee for Coordination of Prospecting for Mineral Resources in Asian Offshore Areas'. It followed that in Bangkok, in February 1966, at the $18^{\text {th }}$ session of the ECAFE Committee on Industry and Natural Resources, the Governments of the Republic of China, Japan, the Republic of Korea and the Philippines agreed to become the founding members of the Coordinating Committee for Offshore Prospecting in Asia, just one year after the idea had been first discussed.

The Government of the Philippines invited the newly established Committee to meet for its first session in Quezon City from 27 May to 2 June, 1966 (Figure 1). This very first session, representing the formal birth of the Committee, was inaugurated by the then Minister of Education of the Philippines Carlos P. Romulo, who was subsequently to become the first Asian President of the General Assembly of the United Nations. Present at the session were the representatives of the four founding-member Governments together with their expert advisers. Also present were representatives of the ECAFE Secretariat, including the Chief of the Mineral Resources Division, C. Y. Li, who was to play a prominent role during the early years of the Committee. At the outset, draft terms of reference for the Committee were formally adopted.

The acronym 'CCOP' was first used in the report of the $4^{\text {th }}$ session of the Committee held in Tokyo in 1968.It reflected the original title of 'Coordinating Committee for Offshore Prospecting in Asia' and has been used ever since when referring to the organization, in spite of several subtle changes in the organization's official title. For example, in 1994, recognizing the broadening of the work programme to more than just offshore prospecting, the Steering Committee considered that the time was ripe for an adjustment to the title of the CCOP and also rewording of its mandate to "The purpose of CCOP 
is to carry out joint applied geoscience programmes for sustainable development of the coastal and offshore areas of East and Southeast Asia". The new title therefore became "The Coordinating Committee for Coastal and Offshore Geoscience Programmes in East and Southeast Asia'.

In 2006, with a further move to onshore as well as offshore projects approved, the name was changed to 'The Coordinating Committee for Geoscience Programmes in East and Southeast Asia'. In spite of the removal of 'Offshore' from the new title, there was no desire to change the now firmly entrenched and durable acronym 'CCOP'.

At present, the mission of CCOP is to facilitate and coordinate the implementation of applied geoscience programmes in East and Southeast Asia in order to contribute to economic development and the improvement of the quality of life in the region. To this end, CCOP promotes capacity building, technology transfer, exchange of information and institutional linkages for sustainable resource development, management of geo-information, geo-hazard mitigation and protection of the environment.

After its initial launch in 1966 it soon became apparent that help would be needed to organize and run such an ambitious venture and by 1970 an application had been submitted for UNDP Special Fund support for a full time technical bureau for the organization which in 1972 became an operational UNDP project, 'Technical Support for Regional Offshore Prospecting'. UNDP support lasted from1972 until finally ending in 1991, and though the UNDP Project was to evolve in a variety of ways it provided CCOP with a vital lifeline until 1987 when CCOP became a fully independent Intergovernmental Organization (Reedman and Shimazaki, 2006)Throughout the twenty years (1972-1991) of UNDP technical support to CCOP, considerable emphasis was placed on training personnel from the Member Countries in various aspects of offshore exploration thus allowing CCOP with its newly establishedinependent status to continue to operate effectively. Today CCOP still maintains a close link with the UN through ESCAP (the successor to ECAFE) with an annual report submitted to the UN Annual Sessions.

\section{Development of the CCOP Network: Member Countries, Cooperating Countries, Cooperating Organizations and CCOP Technical Secretariat}

The Founding Members of CCOP in 1966 were the Republic of China, Japan, the Republic of Korea and the Philippines. It was agreed at the outset that a cautious approach should be taken, on the one hand, to "spreading the activities over too wide an area" but, on the other hand, that other ECAFE members in proximity to the Pacific Ocean would be welcome to join the Committee at the appropriate
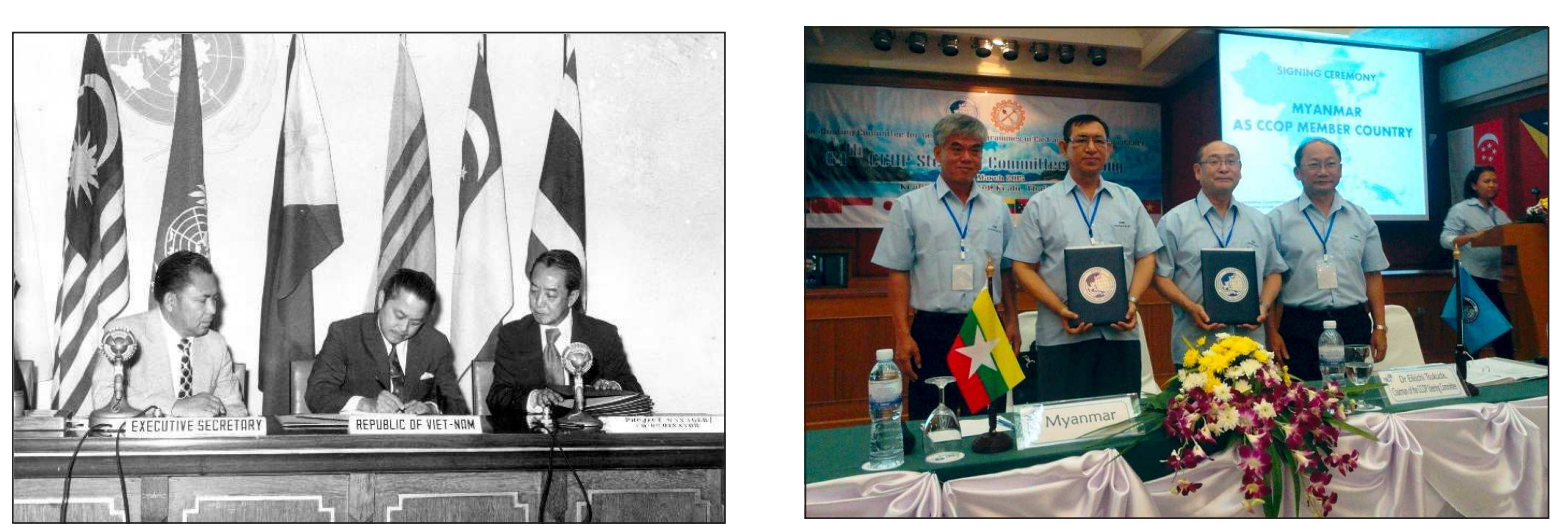

Figure 2. Expansion of CCOP member countries with Republic of Vietnam in 1968 (left), and Myanmar in 2015 (right)
time.This invitation was quickly taken up with Thailand and the Republic of Vietnam joining in 1968, Cambodia and Malaysia in 1969 and Indonesia in 1970 so that after its first five years of existence the Committee already had eight Member Countries. In 1971, the People's Republic of China replaced the Republic of China in the United Nations and therefore became the CCOP Member Country representing China, greatly increasing the total population within the CCOP region. In the 1970s expansion of the Committee continued; Singapore became a member in 1973 and the Pacific Islands Trust Territory became a Member Country in 1975 only to leave in 1981. Papua New Guinea became a member in 1977, so that by 1981 the Member Countries totaled eleven.

This rapid pace of expansion was now to slow down with no new members for almost the next three decades. Expansion, however, was to continue in the next century with Timor Leste (2009), Lao PDR (2011) and Myanmar (2015) joining CCOP, bringing the current total up to fourteen Member Countries. The governing or policy-making body of the organization is the Steering Committee comprising the Permanent Representatives of the 14 Member Countries. They meet twice a year to establish policies and principles which will govern the activities of CCOP, to approve the broad framework of its programme, the budget and accounts for each year, to appoint the Director of CCOP, and receive and consider his reports on the functions delegated to him.

When CCOP was first formed, those developed countries who were members of ECAFE and whose governments actively supported the formation of CCOP, were informally referred to in CCOP documentation as 'supporting countries' but were soon to be formally designated 'Co-operating Countries'. Such countries supplied Special Advisers who attended the early CCOP Sessions and the subsequent Annual Sessions. The original Co-operating Countries were France, Germany, the United Kingdom, and the United States of America, together with Japan who, as the only 'economically developed' Member Country of CCOP in 1966, also provided a Special Adviser. The number of Co-operating Countries has grown steadily since the early years of CCOP and currently (2016) the complete list comprises: Australia, Belgium, Canada, Denmark, Finland, France, Germany, Japan, the Netherlands, Norway, Russia, Sweden, Switzerland, the United Kingdom and the United States of America.

\section{The Technical Secretariat and Technical Advisory Group}

At its first meeting in Quezon City in 1966, the Committee had decided that, as stated in the Terms of Reference, the Committee should have a Technical Secretariat to run the day to day business of the organization.Currently, CCOP Technical Secretariat has 10 permanent 


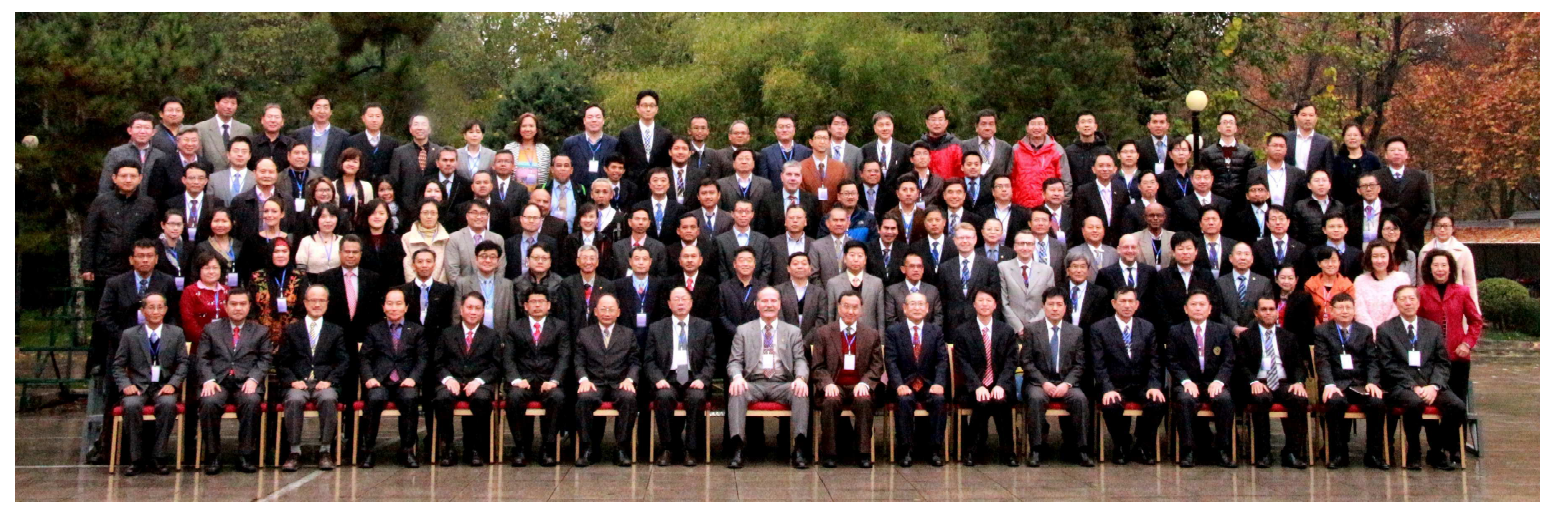

Figure 3. Delegates from CCOP Member Countries and, Cooperating Countries andOrganizations, CCOP Honorary Advisers, and staff of the CCOP TS, at the 51st CCOP AnnualSession in Xi'an, China, November 2015

staff, with the mission to implement the CCOP work programme, seek and administer funds and technical expertise, arrange for CCOP publications and report on CCOP and its programmes to the Steering Committee. The Technical Secretariat is based the CCOP Building within the Thailand Department of Mineral Resources (DMR) complex area, permanently provided by the Royal Thai Government through the kind arrangement of the DMR, Ministry of Environment and Natural Resources.

In order to advise on technical matters and to review programmes drafted by the Technical Secretariat, it was also decided in the first CCOP meeting that a Technical Advisory Group (TAG) should be formed. The TAG was to include experts from advanced countries as 'Special Advisors' and they all helped to steer the Committee successfully through most of its early years of activity. In 1976, on its tenth anniversary, the Committee decided that a number of the experts who had made substantial contributions to CCOP's activities but who had now retired should be nominated, approved and appointed as Honorary Advisers to CCOP. After the first six Honorary Advisers were appointed, this practice of nomination and appointment continues tothe present day (currently 20 Honorary Advisers). Starting from 1978, Advisory Group meetings were held in conjunction with each annual session.

Annual Sessions of CCOP are held once a year, whereas Steering Committee meetings are held twice a year. The most recent annual sessionwas held in Xi' an, People's Republic of China on 24-27 November 2015, with attendance by 109 delegates coming from the Member Countries, Cooperating Countries and Cooperating Organizations. At the meeting, a Strategic Plan and Action Plan for the period of 2016-2020 were finalized and approved, with a focus on activities benefitting society.

\section{CCOP Technical Training and other Projects}

The early Member Countries of CCOP were quick to realize that training should be at the core of their activities in order to improve the competence of the regions indigenous geoscientists. The Geological Survey of Japan (GSJ) played a key role in the regional training center for offshore prospecting which was established by Japan in 1967. Though started as a CCOP project, it was agreed to extend the invitation to participants from other countries of the ECAFE region. Thus the first course, which was held for seven months from 16 May to 11 December 1967, was for ten trainees from seven countries; Indonesia, Korea, Malaysia, the Philippines, China, Thailand, and Vietnam several of which were only later to become
CCOP Member Countries. With very strong support and cooperation from Member and Cooperating Countries, the series of training courses enjoyed an exceptionally long life as a CCOP project. By the time it closed in 1991 it had run continuously for 25 years by which time the Member Countries had become increasingly competent and the project had successfully accomplished its mission. In all, the courses had contributed to the training of a total of 262 young geoscientists from ECAFE/CCOP countries.

While Japan continued to play an important role in the regional capacity building, other member countries and cooperating countries played their part in supporting various projects, notably: Norway and Denmark in petroleum resource management; USA, Germany, UK, France, Sweden, Korea and China in mineral and ground water management; USA, Canada and the Netherlands in coastal zone management.

The CCOP Strategic Plan of 2002 led to the creation of threeprogramme sectors: theGeo-resources, Geo-environment and Geo-information Sectors. The CCOP TS was restructured to be consistent with the Strategic Plan, with each sector having a designated sector manager in each of the Member Countries. A further restructuring of CCOP TS is also one of the recommendations from the Brainstorming Session of the Technical Advisory Group that was conducted in Bangkok in February 2004.

Under the Geo-resources Sector, the Norwegian-funded Petroleum Policy and Management Program (PPM) was implemented from 2002to 2006. PPM was a continuation of CCOP's long cooperation with Norway primarily in the area of oil and gas resource management that had started in the mid-80s. Norway's active involvement in CCOP

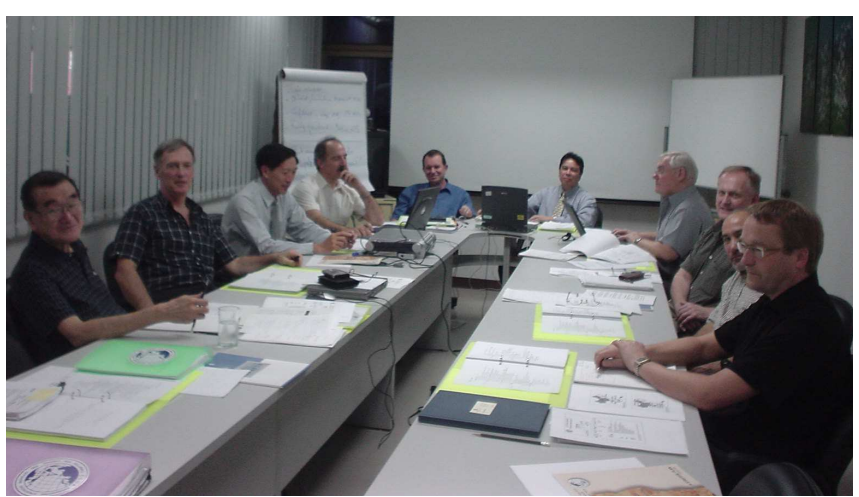

Figure 4: Brainstorming Session of the Technical Advisory Group in February 2004 (CCOP office, Bangkok) 
resulted in the expanded networking wherein the member countries were able to tap in to the wider networks of the Norwegian Petroleum Directorate (NPD) and PETRAD. This also brought Denmark, through DANIDA and GEUS, to support the 3-year Institutional Capacity Building Project ICB-CCOP1) in 2005 - another important project in oil and gas resource management that focused on cross-border cooperation. During this period, local experts from various member countries that were trained during earlier projects and via study grants were at the forefront of the capacity building efforts of CCOP. The above-mentioned projects not only enhanced the capacities of the participating member countries but also have proven that when mutual trust and respect is maintained by all participants, cross-border cooperation can provide a better picture of the geological framework of the studied areas whilst enhancing the knowledge and friendship of the countries involved.

The CCOP region, much of it situated on the 'Pacific Rim', has always been vulnerable to geohazards such as earthquakes and volcanic eruptions often culminating in extensive economic damage and human tragedy. Flooding and landslides have also taken a heavy toll and for these reasons CCOP, in its determination to remain an organisation relevant to the needs of society, has in recent years devoted an ever increasing effort to its geohazard programmes. This emphasis was to be thrown into stark perspective by the tragic events consequent upon the tsunami that struck the coastlines of several CCOP Member Countries on 26 December, 2004. The worldwide response to the tragedy, in which more than a quarter of a million people died, was immediate and overwhelming in the provision of emergency aid but the event had posed some fundamental questions that needed serious discussion and a quick but carefully considered response.

Thailand, together with Indonesia, both Members of CCOP, were two of the worst hit countries and the CCOP Secretariat is based in the capital city of the former. The CCOP Secretariat, jointly with the Department of Mineral Resources (DMR) of Thailand acted quickly, to call for an international Tsunami seminar to consider the role of geoscience in post-tsunami reconstruction and rehabilitation, longer term tsunami mitigation and early warning systems, and public education on tsunami hazards. Support for the seminar quickly came from CCOP Cooperating Countries including Japan (Geological Survey of Japan, AIST), The Netherlands (TNO-National Geological Survey of the Netherlands) and United Kingdom (British Geological Survey). The seminar, held on 31 January-1 February, just five weeks after the tsunami had struck, was opened by the Prime Minister of Thailand and was attended by over six hundred people including sixty foreign experts from fifteen countries while over sixty concerned agencies were represented, twenty five from Thailand and thirty eight from other countries. CCOP had proved it could act quickly in marshalling a geoscientific response to a serious regional problem.

More was to follow, as subsequent to the International Seminar a Project Planning Workshop was held to develop a multinational project to analyze and address both short and longer term needs of the tsunami affected countries. The workshop took place in late March, 2005, in the tsunami ravished resort of Phuket, Thailand, with representatives of Thailand, Malaysia and Japan, and CCOP Cooperating Countries, Canada, Germany, the Netherlands, United Kingdom and the Chairman of the CCOP Advisory Group, Dr. David Prior (USA). A project document was developed during the workshop, focusing on the tsunami hazard as part of a fully integrated collaborative approach to coastal geohazards, with three main initiatives requiring urgent action; risk assessment for forward planning, risk mitigation, and coastal rehabilitation. An agenda had thus been set and, in effect, a challenge issued to the international funding agencies to follow up on their hugely impressive first response to the Tsunami tragedy

Several responses were forthcoming. An eight-month project funded by the Royal Norwegian Government in collaboration with DMR and the Norwegian Geotechnical Institute (NGI) as executing agency entitled "Tsunami Risk Reduction Measures with Focus on Land-use and Rehabilitation" commenced in June 2005. The project was to be completed rapidly because of the urgent need for reconstruction work to commence and practical guidelines for landuse planning in the devastated areas established considering the risk of future earthquake and tsunami events. The three case study areas were in Thailand but the results of the study are intended for use in other parts of the tsunami affected region. The results were presented at a final dissemination seminar attended by three hundred people in Bangkok in March 2006 and also published for much wider dissemination (Figure 34).

Germany has also responded together with DMR in setting up a project aimed at the implementation of high resolution terrain modelling of about $75 \mathrm{~km}$ of tsunami-prone coastline in SW Thailand using advanced remote sensing techniques. The data will be used for tsunami risk assessment and disaster reduction and the project ran to the end of 2006.

CCOP continues to put resources into projects related to natural hazards prediction and management. These projects are resulting in the development of the skills of local government and communities who are in the front line when natural disasters strike. Until today, knowledge in geoscience continues to evolve and to help empower the local communities in the CCOP member countries to predict and mitigate the impact of geohazards.

CCOP projects have also place emphasis on efficient data management. Thus, various Metadata Projects, using internationally recognized standards, have been implemented. These data management projects have been conducted with support from France, USA, Japan, Norway, Korea, China and other partner organizations in the cooperating countries.

The experiences and lessons learned from various data management, hazards mitigation and cross-border resource management projects are helping the next phase of regional projects in $\mathrm{CCOP}$, notably in the areas of geoparks, geological $\mathrm{CO}_{2}$ storage,

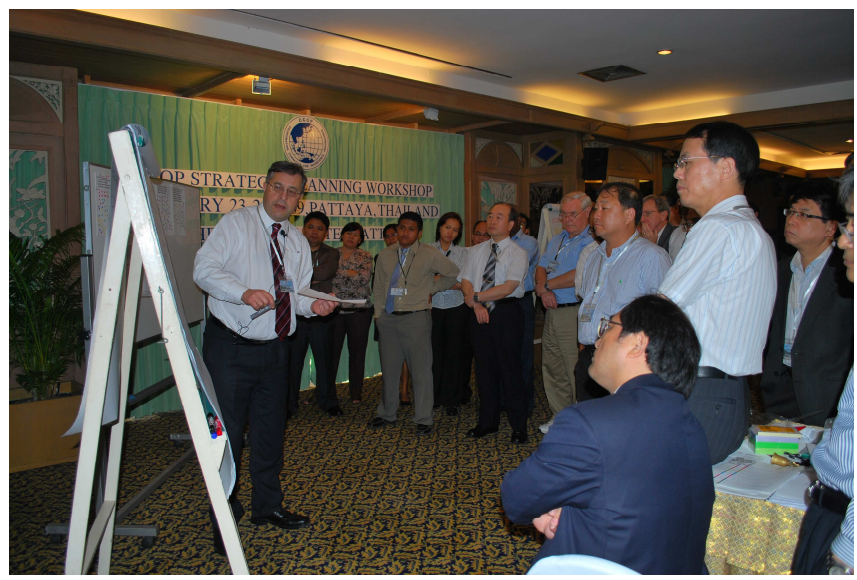

Figure 5: Dr. David Ovadia, former Director for International Cooperation, BGS, facilitating the CCOP Strategic Planning Workshop in 2009 (Pattaya, Thailand) 
harmonized geological standards, groundwater management, sustainable uplanning and coastal zone development, unconventional energy development and other multilateral projects. Clearly, CCOP's aims have evolved from developing geological knowledge for the sustainable development of the region's natural resources to the broader remit of developing geoscience for all of society; with the focus on helping to build safe communities and a more knowledgeable society in the future.

\section{Future for CCOP: Geosciences for Society}

In 2015, CCOP developed a strategic plan covering 2016-2020, adopting the four strategic goals: Outreach - basically information disseminated from CCOP to the outside world informing relevant stakeholders of CCOP's mission and achievements; Cooperation and Partnership - the strengthening of the CCOP network, becoming a natural partner for local/international organizations for jointly executing projects with regional relevance; Knowledge Enhancement and Sharing - giving back to CCOP Member Countries the experience and knowledge gained from the cooperation and partnership; and Data/Information - to provide an excellent basis for acquiring all supporting background data.

Subsequently, an Action Plan was developed to implement the Strategic Plan. Under outreach, CCOP plans ways to deliver science to the public through activities on geoparks, Karst Conservation, Ground-source Heat Pumps and Community-Based Landslide Mitigation. In early 2016, CCOP together with the Geological Survey of Japan published the book "Stone Heritage of East and Southeast Asia". This is the third book published on a heritage theme following 'Geological Museums in East and Southeast Asia' (2011) and the 'Geoheritage of East and Southeast Asia' (2008). CCOP expects that through these activities its stakeholder and client networks will increase as well as distribution of new and existing products and services, making CCOP more visible in East and Southeast Asia and in the world. CCOP will further practice knowledge management in carrying out its activities, as well as exploit the Web for new and improved ways of promoting CCOP work.

For cooperation and partnership, it will continue efforts on enhancing networking and collaborating effectively by expanding the number of CCOP member countries together withcooperating countries and organizations and while maintaining the active participation of its existing members. CCOP will also continue promoting dissemination of the results of projects undertaken within its Member Countries and with other countries and organizations.

On knowledge enhancement and sharing, CCOP will focus on geo-hazards prediction and mitigation, environmental geology, water resources integrated management, energy and mineral resources sustainable development, and geo-information. There are sixteen projects planned from year 2016 to 2020 including ongoing projects. For capacity building, there are ongoing fellowships and training courses offered through CCOP and new subjects will be developed such as medical geology, trans-boundary groundwater management andclimate change adaptation.

In data and information, CCOP will continue to facilitate data sharing efficiently by improving delivery of data and information across boundaries, improving data quality (i.e., integration, consistency and standardization) and developing a culture of knowledge-exchange excellence within the CCOP Technical Secretariat and Member Countries. There are several ongoing projects working towards this end. From 2015, CCOP has officially been a

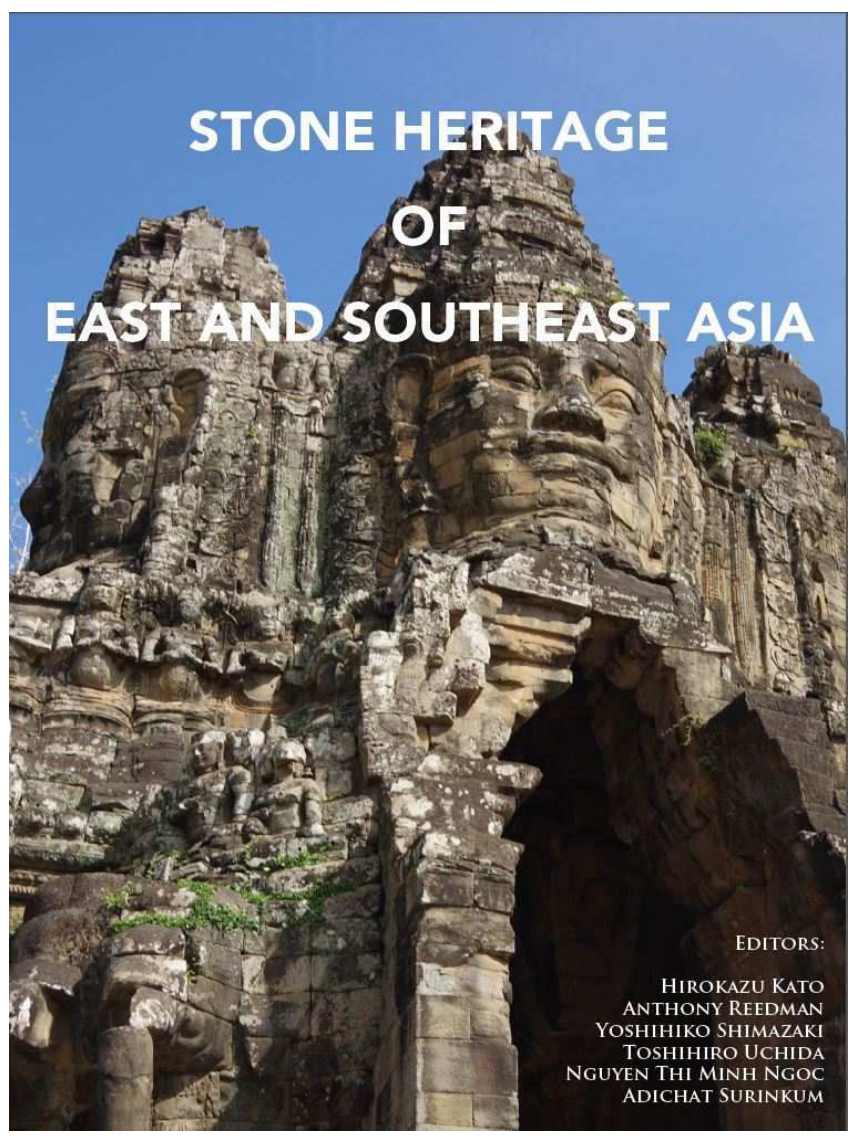

Figure 6: Stone Heritage of East and Southeast Asia - A recent CCOP publication in2016 as a collaborative effort by CCOP member countries

principal member of the One Geology Consortium, and it plans to make better use of the technologies for data sharing used in OneGeology for its member countries. With the support of the Government of Japan, CCOP has embarked on a new project entitled GeoInformation Sharing Infrastructure for East and Southeast Asia (GSi), basically adopting OneGeology technologies, including WebGIS.

CCOP has been in existence since 1966. In that time it has continually adapted its mission to meet the evolving needs of the Member Countries, from surveying and mapping of offshore mineral and energy resources in the region to developing the capacities to effectively assess and promote the development of the region's resources and delineate environmental hazards. This new strategy continues the focus on how geosciences contribute to societyand how CCOP, with our partners, can endeavor to deliver a unique and major contribution to understanding our dynamic Earth so that society can make the right choices to live responsibly within their environment and adapt to environmental changes in the $21^{\text {st }}$ century and beyond.

\section{References}

1. Reedman A. and Shimazaki Y., 2006, A World of Difference, Forty-years of the Coordinating Committee for Geoscience Programmes in East and Southeast Asia (CCOP) 1966-2006.

2. CCOP Strategic Plan 2010-2015

3. CCOP Strategic Plan 2016-2020

4. CCOP Annual Reports from 2002 to 2015

5. CCOP Website: http://ccop.or.th/ 